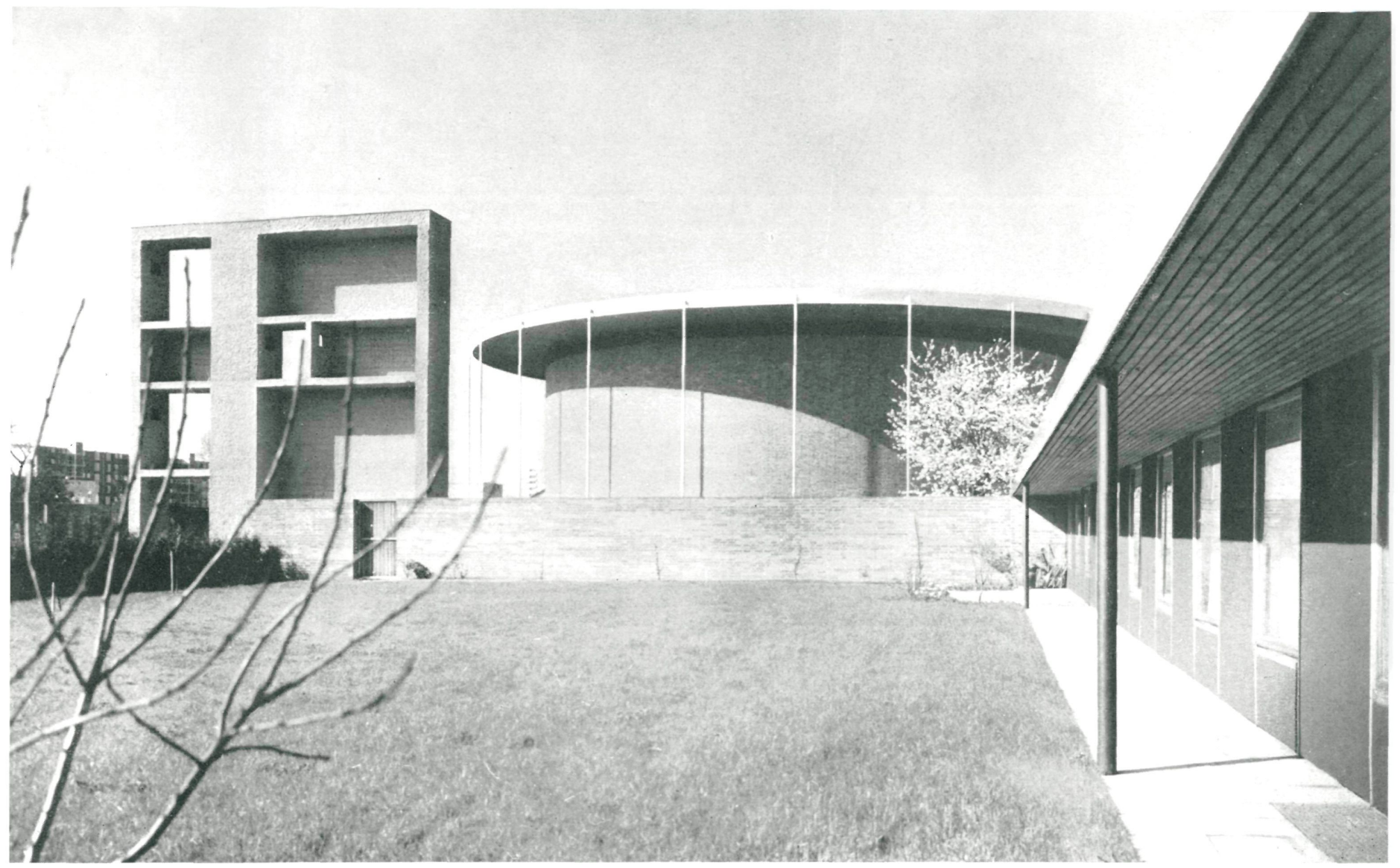

\title{
iglesia \\ de San Juan, en Munich
}

SEP RUF, Prof. arquitecto

$148-90$

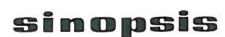

Tiene planta circular de $32 \mathrm{~m}$ de diámetro, y en su interior, y excéntricamente, se ha dis puesto un segundo circulo de $28 \mathrm{~m}$ de diámero, entre ambos se crea un espacio, en forma para co quesiona una serie de dependencias varias y el órgano.

EI complejo construido comprende, además: la sala parroquial, el campanario y el edificio que alberga la vivienda del párroco, oficinas, biblioteca, y salas para grupos juveniles; el sótano de este edificio aloja la instalación de calefacción para todo el complejo.

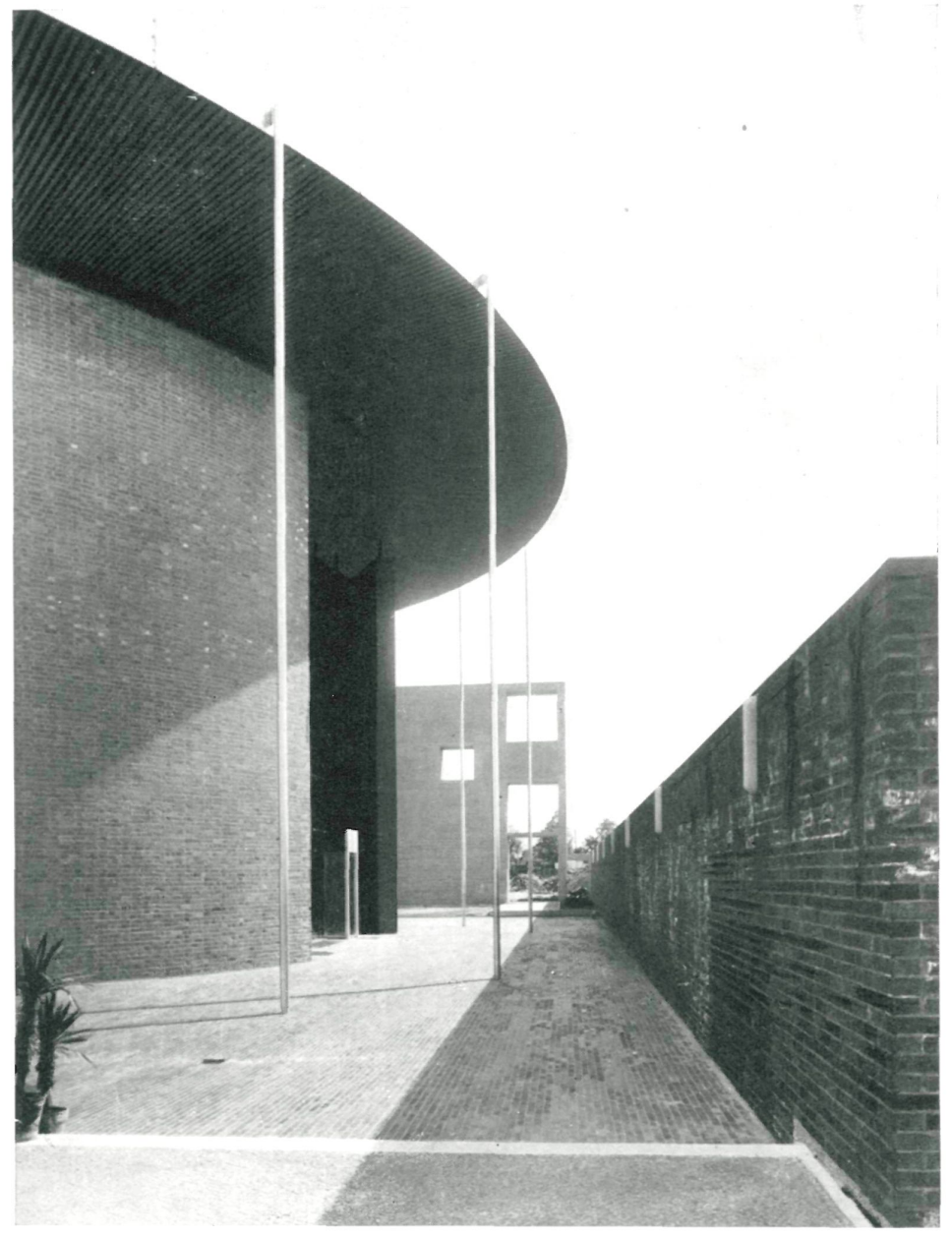




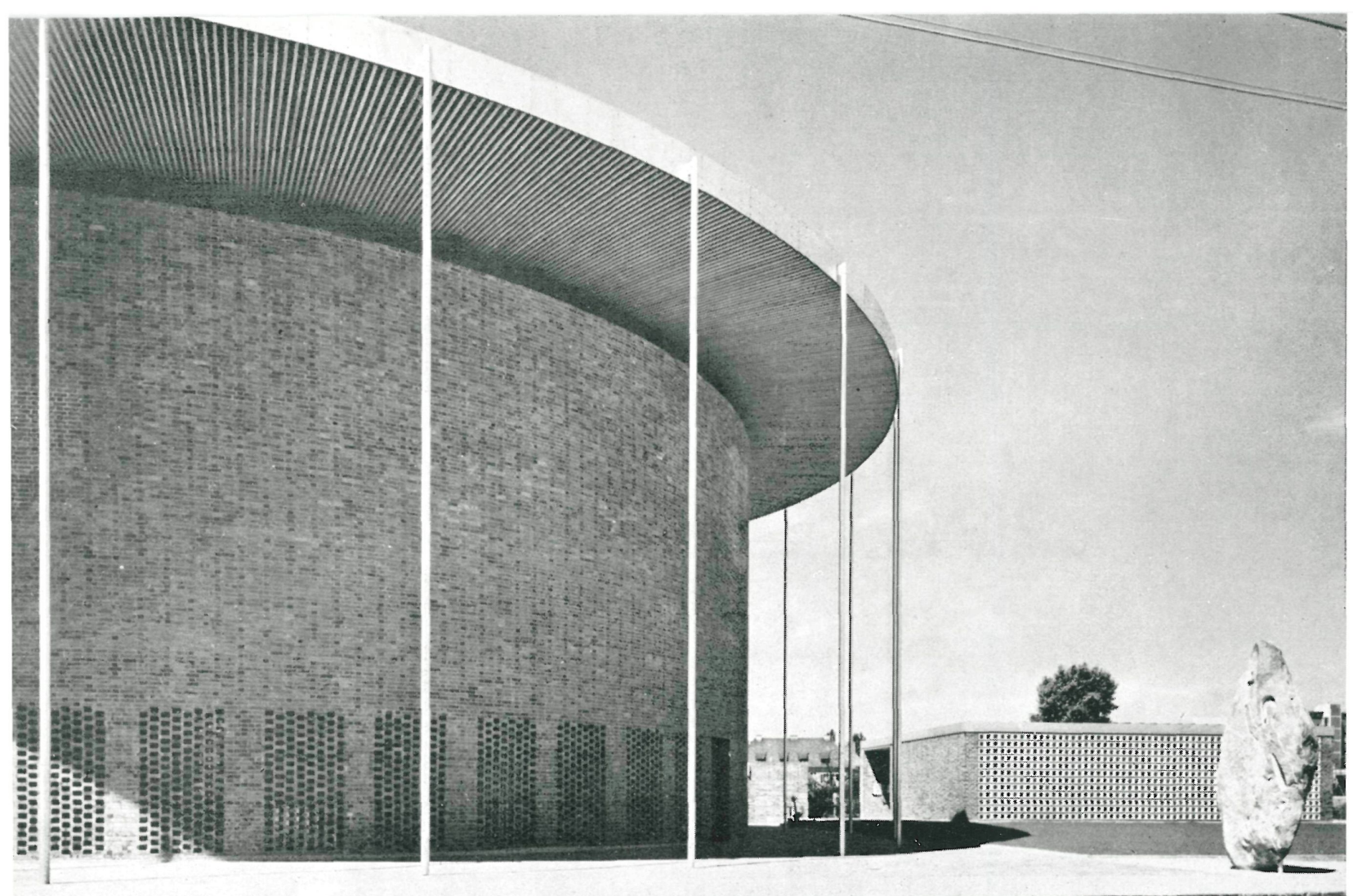
torio del vicario.-3. Baño del vicario.-4. Baño del párroco.-5. Dormitorio del párroco.-6. Habitación 10. 10. Esco - Criada.-12. Asistenta. - 13. Bañdes.-17. Despacho-18. Hermana-19. Conferencias. 20. Accesos -21. Garaje-22. Basuras -B. Campanil. C. Iglesia y sala parroquial: 1. Altar principal.-2. Altar sacramental.-3. Accesos.-4. Vacío.-5. Sacristía. 6. Baptisterio y confesionarios.-7. Entrada.-8. Sala parroquial.-9. Monolito.-D. Seccion por la iglesia: 1. Viga de acero.-2. Cúpula de plexiglás.-3. Anclaje.

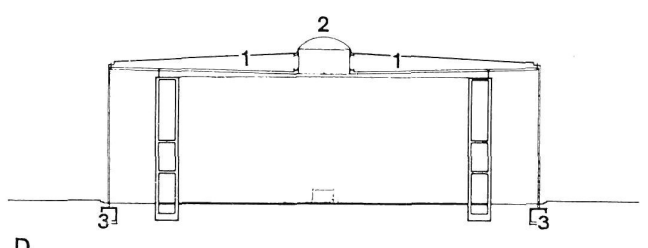

D

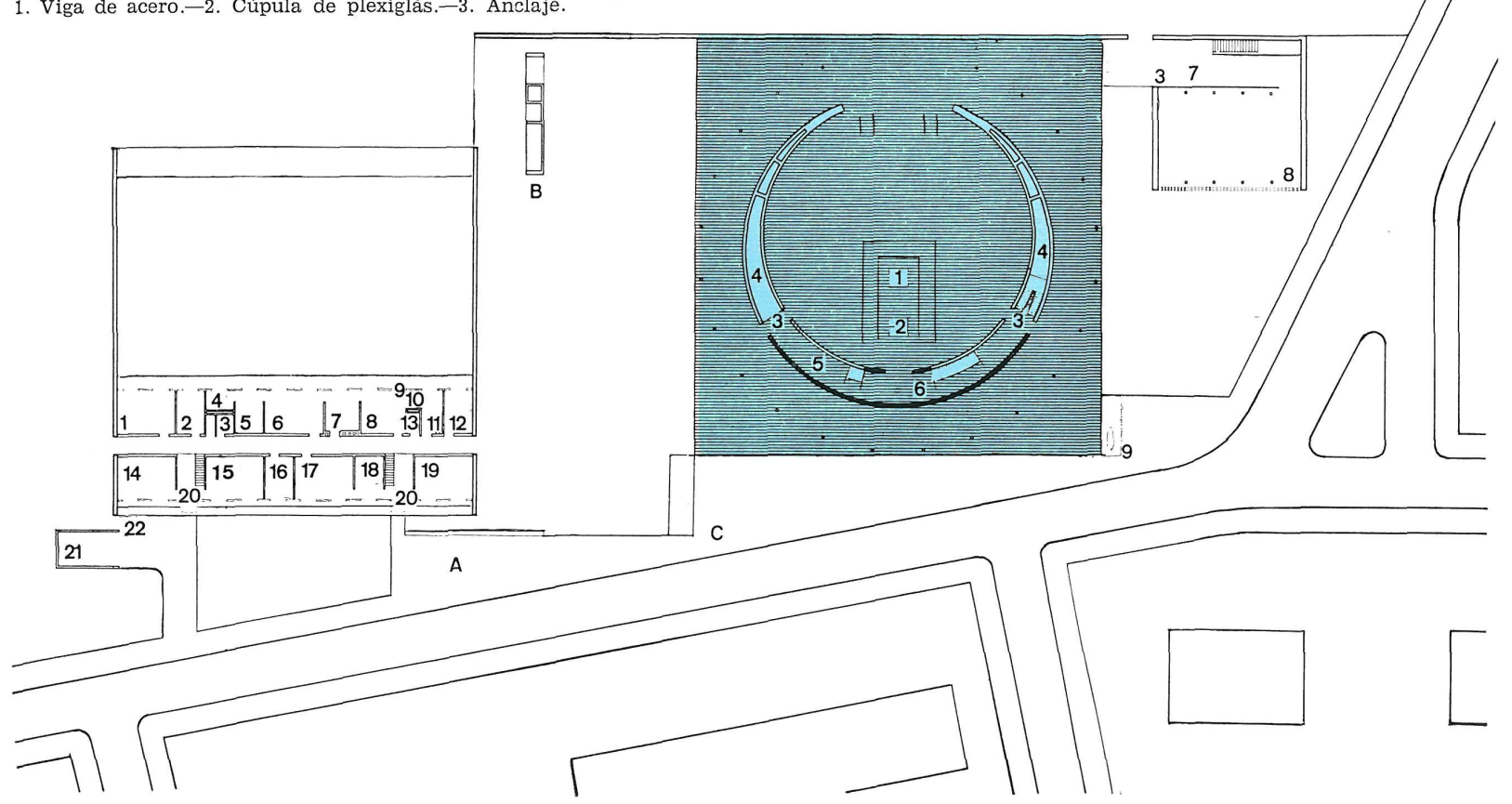

\section{planta general}


La iglesia parroquial de San Juan de Capistrano ha sido construida en medio de un nuevo barrio residencial-Bogenhausen-de Munich.

La planta del "templo" es, en líneas generales, circular: la "forma» más clara y de mayor fuerza simbólica, utilizada desde la antigüedad para expresar la función de algo cerrado dentro de sí mismo.

Sin embargo, esta forma geométrica-que es el elemento más importante-se presenta bajo un aspecto original y modificado. Dentro de un círculo de $32 \mathrm{~m}$ de diámetro se ha dispuesto otro, de $28 \mathrm{~m}$ de diámetro, situado excéntricamente respecto al anterior, pero de manera que entre los dos se crea un área aprovechada para organizar una serie de dependencias. Este espacio en forma de hoz crece hacia el E. hasta una anchura de $4 \mathrm{~m}$, mientras que en el O., en el portal de la iglesia, se unen los dos círculos dejando una entrada de $16 \mathrm{~m}$ totalmente acristalada.

La cúpula, que está situada en el centro del círculo exterior, resulta original y excéntrica desde el espacio interior.

La iglesia, edificada sobre esta planta, es un cilindro completamente cerrado y uniforme.

El muro exterior, construido a base de fábrica de ladrillo cocido y con una altura de $12,50 \mathrm{~m}$, se proyectó sin ventanas; solamente en su parte inferior hay unas celosías que dejan pasar la luz del día a las dependencias secundarias, sin perjudicar la uniformidad del conjunto.

La cubierta descansa sobre una estructura metálica, tiene forma de bóveda muy plana y va revestida, por su exterior, de chapa de cobre y coronada por una cúpula, de $5 \mathrm{~m}$ de diámetro, de plexiglás.

Dicha cúpula se eleva $4,5 \mathrm{~m}$ sobre el nivel superior del muro de cerramiento, apoyándose en un arco metálico del que parten los esbeltos soportes también metálicos, situados $5,35 \mathrm{~m}$ entre ejes.

Dichos soportes, aparte de su misión específica, presentan un valor estético al acentuar el carácter de "circuito" que siguen las procesiones que discurren por el ligero pórtico así formado.

El suelo lleva pavimento de ladrillos de un color rojo cálido, igual que en el interior.

Las puertas laterales de madera, revestidas de cobre, conducen a las dependencias secundarias y al interior de la iglesia.

La entrada $\mathrm{O}$. aparece completamente acristalada con Securit.

La idea tomada como base para la construcción de la iglesia se manifiesta de forma más acentuada todavía en el interior.
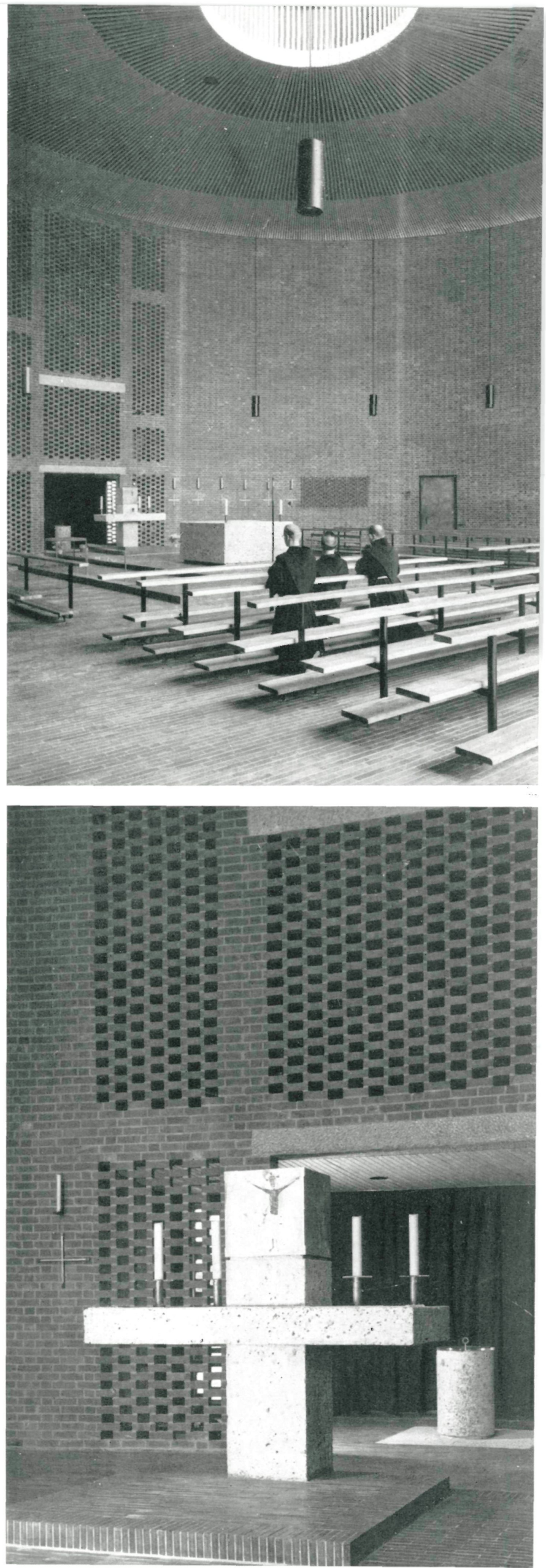


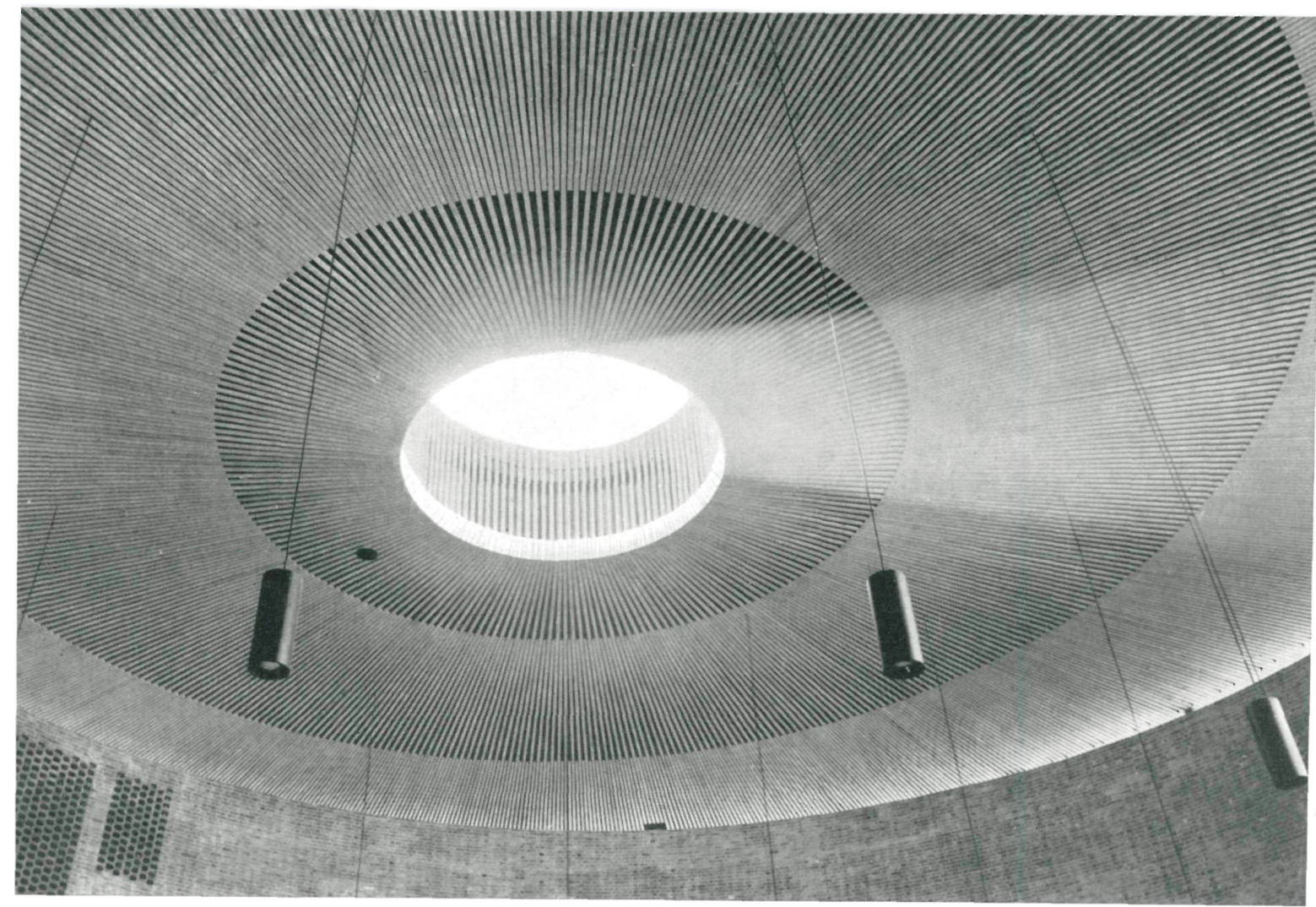

Sobre un estrado de poca altura, que se extiende desde el E. hacia el centro de la iglesia, están los altares: debajo de la cúpula, el altar del Santo Sacrificio, y al E., el altar Sacramental.

En el espacio intermedio entre los dos círculos-que, como hemos dicho, tiene forma de hozse distribuyen. en la planta baja, la pila bautismal, una capilla para confesionarios en cada lado, la sacristía y dependencias auxiliares, y en la planta superior, el órgano.

El techo está revestido de madera en colores claros, cons. tituyendo bandas de listones colocados en dirección radial.

El complejo parroquial comprende, además, edificios secundarios: la sala parroquial, situada en la parte NO. del terreno, que es un edificio de planta cuadrada-16 $\times 16 \mathrm{~m}-$ de $4 \mathrm{~m}$ de alto, construido de fábrica de ladrillo, y que presenta, en su alzado O., una celosía de hormigón y vidrios de color. Desde la sala parroquial, un muro de ladrillo, de $3,25 \mathrm{~m}$ de altura, conduce al campanario, con tres campanas, constituido por una pared de $12,5 \mathrm{~m}$ de ancho $\mathrm{y}$ $13,5 \mathrm{~m}$ de altura.

Finalmente, en la parte S. del terreno está el edificio que alberga: la vivienda del párroco, oficinas, biblioteca y salas para grupos juveniles. En el sótano se aloja la instalación de calefacción para todo el complejo.

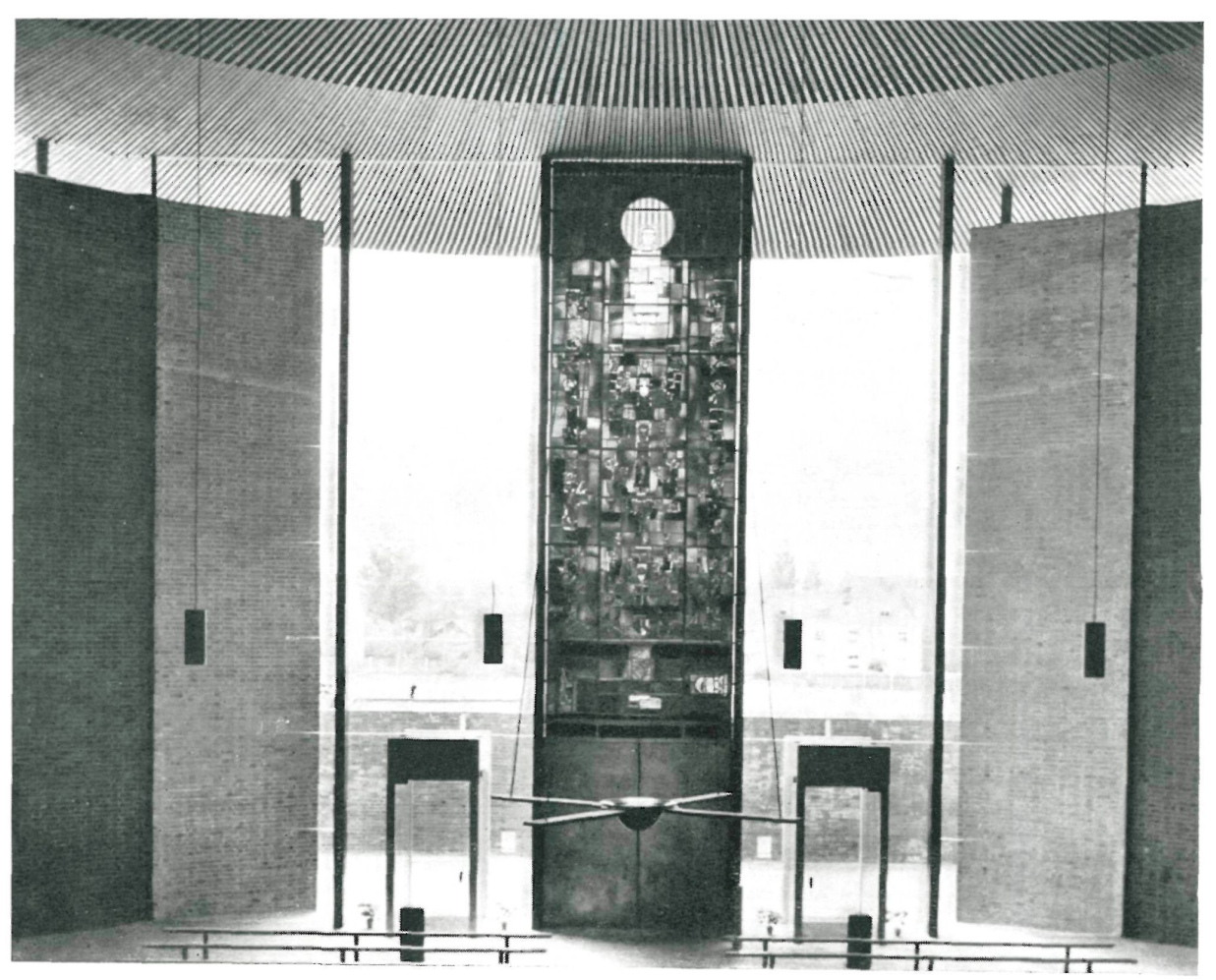

Fotos: GRETL WOGLER 
Eglise Saint Jecum, ต้ Mumich

Sep Ruf, Prof. architecte.

Cette église de forme circulaire a $32 \mathrm{~m}$ de diamètre et, excentriquement, un autre cercle de $28 \mathrm{~m}$ de diamètre a été disposé. Entre ces deux circonférences se trouve créé un espace en forme de faucille qui abrite le baptistère, une chapelle pour les confessionnaux de chaque côté, la sacristie, l'orgue et une série de dépendances variées.

L'ensemble construit comprend de plus la salle paroissiale, le clocher, l'édifice que abrite le logement du curé, les bureaux, une bibliothèque et une salle pour les groupements de jeunesses. Dans le sous-sol de cet édifice se trouve l'installation de chauffage pour tout l'ensemble.

\section{Soint Jolhm"s Chumch, im Mumiclo}

Sep Ruf, Prof. architect.

This church is built on a circular plan, and within its interior, excentrically located, a second circle, of $28 \mathrm{~m}$ diameter has been disposed. Between the two, there is a scythe shaped space which houses the baptistry, a chapel for confession boxes, a sacristy, an organ, and various annexes.

In addition, the following features are also included in the total project: the parrochial hall, the campanile, the building housing the priest's home, offices, a library, and rooms for juveniles. The heating installation for the whole project is located in the cellar.

\section{St. Jolhcum Kinche in Muinchen}

Sep Ruf, Prof. Architekt.

Der Grundriss der Kirche ist ein Kreis von $32 \mathrm{~m}$ Durchmesser. In ihrem Innern hat man einen zweiten exzentrisch angelegten Kreis von $28 \mathrm{~m}$ Durchmesser vorgesehen, der zusammen mit dem ersten einen sichelförmigen Raum bildet, in dem sich die Taufkapelle, Beichstühle, die Sakristei, eine Reihe von Nebenräumen und die Orgel befinden.

Ferner enthält der Kirchenkomplex einen Pfarrsaal, den Glockenturm und ein Gebäude mit der Wohnung des Pfarrers, Büroräumen, Bibliothek und Gemeindesaal. Im Keller dieses Gebäudes ist die Heizung für den ganzen Komplex untergebracht. 